\title{
Repertorio de formas imaginarias de lidiar con la urbe*
}

\begin{tabular}{|c|c|}
\hline \multicolumn{2}{|c|}{ Fecha de recepción: 20 de abril de 2015 Fecha de aceptación: 24 de Julio de 2015 Disponible en línea: 30 de octubre de 2015} \\
\hline \multicolumn{2}{|c|}{ Luis Campos Medina } \\
\hline Doctor en Sociología & Académico del Instituto de la Vivienda, Facultad de Arquitectura y Urbanismo \\
\hline \multicolumn{2}{|l|}{ Universidad de Chile } \\
\hline \multicolumn{2}{|c|}{ Paulina Rojas Moreno } \\
\hline Socióloga & Investigadora independiente \\
\hline
\end{tabular}

Resumen Mediante el análisis temático de un conjunto de microrrelatos publicados por el concurso literario "Santiago en 100 palabras", realizado en Santiago de Chile desde 2001, en este artículo abordamos las maneras en que los habitantes de la ciudad hacen frente a la vida urbana contemporánea. La idea de lidiar con la urbe resulta propicia para describir la relación problemática que mantienen los urbanitas con su ciudad y la noción de repertorio posibilita una comprensión de conjunto de las distintas expresiones que esta experiencia adopta. Como conclusión proponemos, primero, que las formas de lidiar con la urbe adoptan tres modos típicos en los microrrelatos. Segundo, que los microrrelatos dejan ver una secuencia causal en la manera como se experimentan subjetivamente los problemas de la vida urbana. Tercero, que la producción de representaciones e imaginarios urbanos adopta una forma agregativa que parece plausible extrapolar a otros ámbitos.

Palabras clave imaginarios urbanos; microrrelato; repertorio; representaciones de la ciudad; Sociología Urbana 


\section{Repertoire of Imaginary Ways to Deal with the City}

Abstract Through the thematic analysis of a set of flash fiction stories published by the "Santiago in 100 Words" (Santiago en 100 palabras) literary competition, held in Santiago de Chile since 2001, in this article we discuss the ways in which city inhabitants face the contemporary urban life. The idea of dealing with the city is conducive to describe the problematic relationship that city dwellers have with their urban space. The notion of repertoire enables a global understanding of all the different expressions that this experience adopts. As a conclusion we propose, first, that the ways of dealing with the city adopt three typical ways in flash fiction stories. Second, that the flash fiction stories reveal a causal sequence in the way they subjectively experience the problems of urban life. Third, the production of urban and imaginary representations adopts an aggregative way that seems plausible to extrapolate to other areas.

Keywords urban imaginaries; flash fiction story; repertoire; representations of the city; Urban Sociology

\section{Repertório imaginário de maneiras de lidar com a cidade}

Resumo Mediante análise temática de um conjunto de microrrelatos publicados pelo concurso literário "Santiago em 100 palavras", realizado em Santiago de Chile desde 2001, neste artigo abordamos as formas em que os habitantes da cidade fazem frente à vida urbana contemporânea. A ideia de lidar com a urbe resulta propicia para descrever o relacionamento problemático mantido pelos urbanitas com a sua cidade e a noção de repertório possibilita uma compreensão de conjunto das diferentes expressões que tal experiência assume. Em conclusão estamos sugerindo, primeiro, que as formas de lidar com a urbe adotem três jeitos típicos nos microrrelatos. Segundo, que os microrrelatos deixam ver uma sequência causal na maneira como os problemas da vida urbana são experimentados subjetivamente. Terceiro, que a produção de representaçóes e imaginários urbanos adota uma forma agregativa que parece plausível extrapolar para outros âmbitos. 


\section{Introducción}

En su libro Especies de espacios, Georges Perec (1974) sugería cautela a la hora de proponer una definición de la ciudad: es una entidad demasiado grande para intentar definirla de una sola vez. A eso podríamos agregar que las experiencias de vida en la urbe son diversas y variadas, lo que hace aún más improbable alcanzar una noción integral y satisfactoria. Para hacer eco del consejo de Perec, en este artículo no pretendemos entregar una definición de la ciudad ni una descripción exhaustiva de las maneras de hacer frente a los tipos de relaciones y experiencias problemáticas propios de la vida urbana actual. Buscamos, más bien, efectuar una aproximación al estudio de la experiencia de lidiar con la urbe, por medio del análisis de las situaciones imaginarias narradas por los habitantes en textos literarios ultrabreves (Lassave, 1998; 2002), en la perspectiva de lo que Barrère y Martuccelli (2009) denominan la "técnica del redoblamiento" (p. 343), es decir, aquel modo de análisis de textos literarios cuyo objetivo es encontrar en la obra aquello que la teoría sociológica ya conoce, para así producir una suerte de ilustración adecuada.

En efecto, en este trabajo nos basamos en el análisis de un corpus de 595 microrrelatos publicados en el marco de "Santiago en 100 palabras", un popular concurso literario organizado por la revista Plagio, el Metro de la ciudad de Santiago y la empresa Minera Escondida, que se ha realizado sin interrupción desde el año 2001. Su convocatoria, dirigida a todos los habitantes de la ciudad y del país, ha sido para escribir cuentos breves de un máximo de cien palabras, sobre la ciudad de Santiago o la vida urbana contemporánea en general. Con una convocatoria tan amplia, los temas abordados en los microrrelatos son muy variados.

Por otra parte, el concurso invita a participar para obtener alguno de los reconocimientos ofrecidos: tres premios en dinero para los tres primeros lugares y la publicación, como menciones honrosas, de otros ocho cuentos breves ${ }^{1}$. Aunque la denominación utilizada por los organizadores es la de "cuentos breves", nos parece más adecuado hablar de microrrelatos, pues se ajusta mejor a las características de los textos del concurso, entre los cuales se observa una variedad de formas que no siempre se acomodan a la estructura de un inicio, un desarrollo y un desenlace, típica del microcuento y que, como lo recuerda Fernández (2005), constituye "la clásica estructura triádica de la secuencia narrativa” (p. 127).

El conjunto de estos once microrrelatos premiados en cada versión es publicado en las estaciones, en afiches de gran formato u otros más pequeños dentro de los vagones del Metro. En ambos casos, los soportes utilizados son los mismos destinados a los afiches publicitarios expuestos en el ferrocarril subterráneo. Además de los microrrelatos ganadores, cada dos años los organizadores del concurso editan un pequeño libro denominado Los 100 mejores, con los que, a su juicio, constituyen los cien mejores microrrelatos de los dos años precedentes, incluidos los ganadores publicados en los afiches. El material de análisis que hemos utilizado en esta ocasión está compuesto por estos microrrelatos 
publicados por el concurso en los libros de bolsillo: un corpus de 595 textos, seleccionados entre los años 2001 y 2012.

Hicimos un análisis para cada microrrelato, entendido como una muestra singular de la experiencia urbana, pero también un análisis agregado, para identificar recurrencias y repeticiones y hacer plausible la idea de un repertorio teórico de experiencias. La idea de "repertorio" fue tomada de Becker y Faulkner (2011, p. 278), como un esbozo del conjunto de formas principales en que los habitantes deben hacer frente al Santiago de nuestros días. La exhaustividad, por lo tanto, no es una de nuestras pretensiones.

Según estos autores, la noción de repertorio ha sido incluida en los estudios sociológicos para indicar que las personas actúan en situaciones específicas y siempre tienen la posibilidad de "elegir lo que harán entre una variedad de alternativas que les propone la sociedad o la cultura" (p. 278). Los autores citan a Tilly para plantear que el repertorio alude al "conjunto limitado de rutinas que se aprenden, se comparten y se ejecutan a través de un proceso de elección relativamente deliberado" (Tilly, 1995, p. 27, citado en Becker y Faulkner, 2011, p. 280). Como el repertorio se produce y actualiza mediante las ejecuciones de los individuos en situación, siempre se encuentra "en proceso": se hace y rehace continuamente. De acuerdo con los planteamientos de Becker y Faulkner, entonces, consideramos que con el análisis de los microrrelatos es posible esbozar el conjunto de las "concepciones generalizadas de comportamiento social" vinculadas al lidiar con la ciudad. En otras palabras, es posible registrar las formas típicas de comportamiento colectivo (Wirth, 1984, p. 270) que imaginan los urbanitas como propias de la experiencia de hacer frente a la ciudad y la vida urbana contemporánea: el repertorio imaginario de formas de lidiar con la urbe.

\section{Metodología}

Para hacer este análisis procedimos de un modo simple, pero minucioso: efectuamos múltiples lecturas de un corpus de 595 microrrelatos publicados por los organizadores del concurso entre los años 2001 y 2012, en el formato de libros de bolsillo. En dichas lecturas identificamos los microrrelatos que narraban una situación en la que uno o varios habitantes de la ciudad debían "lidiar" con la ciudad en cualquier plano. Se entendió la noción de "lidiar" de un modo amplio, vale decir, como la forma en la que los habitantes de la ciudad deben hacer frente a relaciones y experiencias urbanas, por cuanto se encuentran "arrojados" en ella. A esto se agregó una idea presente en la definición que el diccionario de la Real Academia Española entrega de la palabra lidiar, cuyas distintas acepciones comparten la idea de que aquello con lo que se lidia es algo desagradable y molesto. Con independencia de ese carácter molesto, este hacer frente puede ser previsto y calculado o bien consistir en un dejarse llevar casi pasivo. No obstante, lo central es la presencia de ambos componentes: un objeto desagradable que se presenta a la experiencia y un modo de hacerle frente por parte de quien lo vivencia.

Una vez determinados los microrrelatos que mostraban situaciones en las que los habitantes de la ciudad debían hacer frente a ella (61), procedimos a identificar el tema principal de cada uno o, dicho con otras palabras, el foco de referencia temático propuesto en la historia y respecto al cual se expresaba la acción de lidiar. Este procedimiento nos permitió seleccionar este conjunto de 61 microrrelatos como una "constelación temática”, es decir, como un grupo de elementos entre los cuales se puede identificar un vínculo de sentido que posibilita la hipótesis de considerarlos como un grupo (Campos, 2011), así como identificar subgrupos temáticos y clasificar 
los microrrelatos de acuerdo con ellos. De esto se desprende que la perspectiva analítica que escogimos fue la del análisis temático, aunque en una variante ad hoc. En efecto, el análisis temático propone centrarse en:

[...] el contenido de la narrativa y su relación con recursos lingüísticos y culturales disponibles en esa sociedad. Es la perspectiva que intenta responder la pregunta por el ¿qué se narra?, atendiendo al significado del relato con el propósito de crear categorías analíticas (Bernasconi, 2011, p. 22).

En otras palabras, el contenido del microrrelato fue el eje de nuestro análisis, puesto que decidimos centrarnos en el told en lugar del telling (Riessman, 2008, p. 54). Un trabajo inspirador de este procedimiento es el de Chalvon-Demersay $(1996 ; 1994)$ en su estudio de series de televisión emitidas en canales franceses durante la década del noventa ${ }^{2}$.

La noción de constelación temática remite a un espacio asociativo y propone la idea de un vínculo entre sus elementos de acuerdo con los criterios de pertinencia y adecuación, que solo pueden establecerse en referencia a un sustrato cultural compartido, como la idea de "código" propuesta por Barthes (1985, p. 354). El uso de dicha noción supone ir construyendo grupos de elementos de modo inductivo. Este procedimiento, como cualquier forma de clasificación, es relativamente arbitrario; sin embargo, a nuestro juicio, posee dos virtudes que vale la pena rescatar: primero, indica la diversidad de voces y perspectivas a partir de las cuales se habla de la ciudad y, por lo tanto, es coherente con la polifonía que caracteriza la vida urbana (Mondada, 2000, p. 41). Segundo, cada constelación indica una manera de referirse a la ciudad de acuerdo con un determinado aspecto (Searle, 1982), lo que equivale a decir que se trata de formas parciales de "legibilidad" de la ciudad
(Stierle, 2001), de acercarse a su comprensión, en este caso, sociológica.

\section{Análisis}

En la constelación temática denominada "formas de lidiar con la urbe" agrupamos distintos microrrelatos que pueden ser distinguidos, en principio, según dos grandes tipos: aquellos que aluden a situaciones relativas a problemas de la organización de la ciudad (por ejemplo, problemas con el transporte público o la delincuencia) y los que aluden a los modos de relacionarse que caracterizan el estilo de vida capitalino. Estos grupos corresponden a lo que suele distinguirse como urbs y civitas: la ciudad es tanto la forma urbana y arquitectónica (urbs), como las relaciones humanas y los vínculos políticos (civitas). El segundo grupo es mayor en términos cuantitativos y exhibe una mayor diversidad interna en cuanto a sus contenidos; es a la descripción de este último que consagraremos las páginas que siguen, puesto que su cantidad y su variedad sugieren que tiene mayor relevancia y significado para los participantes en el concurso a la hora de expresar las maneras en las que deben lidiar con la ciudad. Sin embargo, comenzaremos por referir brevemente a los primeros, subgrupo al que hemos denominado "Problemas de la urbe".

\section{Problemas de la urbe}

Bajo esta denominación agrupamos aquellos microrrelatos que refieren hechos o circunstancias que complican la vida de los habitantes de la ciudad y cuyo origen se encuentra en los modos de organización de esta última. Esta idea de modos de organización indica que los problemas aludidos forman parte de ciertos dominios de acción pública o "sectores" (Muller, 2010), en los que hay actores institucionales responsables de 
establecer las reglas del juego (Fernándes, 2014) $\mathrm{y}$, en consecuencia, indica los modos como la acción institucional y las políticas públicas dan forma al espacio y territorio que habitan los urbanitas (Aliste y Musset, 2014; Friedmann, 1997; Limón, 2014). Los problemas de la urbe se refieren, en la mayoría casos, a cuatro subgrupos: a) la contaminación (Boisier, 1989; Irarrázaval, 2012); b) la delincuencia (Moser y McIlwaine, 2006; Koonings y Kruijt, 2007; Carrión y Núñez-Vega, 2006); c) la pobreza (Lewis, 1988; Sabatini et. al., 2012), y d) el transporte y los accidentes de tráfico (Correa, 2010; Iracheta, 2011).

Cabe recordar, como lo hace Musset (2007), que la ciencia ficción, en particular la ficción literaria, ha abordado con persistencia los problemas y las disfuncionalidades de las ciudades contemporáneas.

Acerca de la contaminación, casi todos los microrrelatos que tratan este tema abordan la contaminación del aire, en especial del esmog que cubre la ciudad de Santiago y hace de ella una de las ciudades más contaminadas de América. Esta situación es experimentada de forma muy vívida por los habitantes durante los meses del invierno santiaguino (junio, julio y agosto).

\section{Fin de semana}

Ese viernes de alerta ambiental, la Virgen cerró los brazos y bajó del cerro. Caminó hacia el Metro. Lo tomó y llegó a la Estación Central. Se subió al tren. Se bajó en Temuco y respiró profundo. Miró hacia arriba y se dio cuenta de que el cielo era azul. Repitió esto tantas veces, que llegó el domingo. Volvió al tren. Se subió. Se bajó en la Estación Central. Tomó el Metro y llegó al cerro. Subió y abrió los brazos. Nadie se dio cuenta de que ella no había estado ahí. Había alerta ambiental.

Carolina Vega, 29 años, Peñaflor.

En relación con la delincuencia, la mayoría de los microrrelatos que tocan este tema hablan de robos, delitos que son cometidos en contra de un habitante de la ciudad en situaciones normales, como caminar por la calle, desplazarse en el transporte público, etc. Aluden, en consecuencia, al actuar de los carteristas. Los microrrelatos que abordan formas más sofisticadas u organizadas del crimen son casi inexistentes, lo que indica que la escala de percepción de la delincuencia es más bien cara a cara.

\section{Paseo Ahumada}

Corres sin un rumbo definido, corres para lograr salvar lo que llevas en tus manos, corres para cuidar tu libertad y continuar el nuevo día. Corres, corres y te pierdes en medio de la gente. Y mientras tú corres yo estoy parada en medio del Paseo Ahumada mirándote como te llevas mi cartera.

Daniela Montecino, 25 años, Santiago.

A propósito de la pobreza, el tratamiento hecho por los microrrelatos es destacar la falta de recursos materiales de los habitantes de la ciudad de Santiago, cuestión que les impide llevar una vida decente. A veces, estos textos adoptan un tono de denuncia de las injusticias y otras, un tono triste, que expresa una especie de resignación. Sin embargo, en ambos casos, estos microrrelatos nos muestran la capacidad de acción que tienen los habitantes en relación con las situaciones de pobreza, capacidades que son importantes, en algunos casos y casi nulas, en otros.

\section{El taxista}

"Está mala la cosa". Su mano lenta encendió el taxímetro. "Con decirle que ayer no pude parar la olla. Me levanté cuando todavía estaba de noche y llegué cuando ya estaba oscuro. No llegué con na’. Mi mujer trata de arreglárselas, pero no puede. Y mi niñita está más flaca. Creo que está enferma”. Se sobó la barbilla miserablemente afeitada. El asiento trasero vacío en el espejo retrovisor tornó patética su confesión. La calle mezquina no atraía pasajeros... una vez más. Detuvo el llanto con el cigarro. "Está mala la cosa”, murmuró para él. Su mano lenta apagó el taxímetro.

Rodolfo Depix, 24 años, Santiago.

Con respecto a los accidentes de tránsito, los microrrelatos muestran una especie de diagnóstico compartido: durante los primeros siete años del concurso, se consideraba que la situación del 
transporte en la ciudad era muy desorganizada, que la infraestructura urbana (vías de transporte) se encontraba en muy mal estado y los principales responsables de esta situación eran los autobuses del transporte público, llamado "micros amarillas". Esto es importante porque en febrero de 2007 el Ministerio de Transporte cambió todo el sistema de transporte de la ciudad y creó el Transantiago. Desde entonces, los problemas planteados son, sobre todo, relativos al hacinamiento $y$ colapso en cuanto a la cantidad de usuarios del transporte público, sin que necesariamente se hayan modificado los problemas indicados en los primeros siete ańos del concurso. Es lo que nos muestra el microrrelato "Lata de sardinas".

\section{Lata de sardinas}

Y cuando pensé que ya no había espacio, se subieron dos más.

Rayén del Pino, 19 años, San Miguel.

En la perspectiva de los "Problemas de la urbe", la ciudad es considerada como un espacio físico de acción humana; un espacio complejo que acoge la vida de las personas, pero no proporciona las condiciones adecuadas para su desarrollo. No obstante, como ya indicamos, la mayoría de los microrrelatos refiere a otro tipo de problemas: aquellos que amenazan y crean dificultades para la sociabilidad de los habitantes de la ciudad y, en muchos casos, les impide ser felices. En estos textos observamos una especie de crítica a la "lógica propia a la sociabilidad urbana, según la cual los principios de transparencia, reciprocidad y plenitud en las interacciones dan paso a sus opuestos: la opacidad, la contigüidad, la multiplicidad" (Grafmeyer y Joseph, 1984, p. 42. Traducción propia). Se trata, en este sentido, de problemas de la vida en la ciudad, que remiten a los vínculos y las relaciones interpersonales o a los modos de relacionarse que caracterizan el estilo de vida capitalino.

El grupo más significativo de microrrelatos nos habla de problemas relacionados con lo que L. Wirth (1984) abordó en su clásico texto de 1938
"El fenómeno urbano como modo de vida", en el cual plantea que uno de los rasgos distintivos de la vida urbana es la asociación entre proximidad física y distancia social, que tiene como consecuencia acentuar la reserva mutua entre los habitantes de la ciudad y puede llegar a engendrar soledad. El modo de vida urbano, para Wirth, remite a cuestiones de orden material, como las que acabamos de mencionar en "Problemas de la urbe". Especial relevancia cobran otras dos dimensiones, que corresponden a la organización social y al conjunto de ideas y actitudes. Con base en estas dos últimas, emerge con claridad que la ciudad no es solo un objeto material, sino que es el resultado de la acción de los habitantes, un producto organizado y con sentido. De hecho, es en esas dimensiones que la ciudad se presenta a veces como una estructura que se impone a los habitantes o, a decir de Morand (1977), que la ciudad se convierte en un "poder supraindividual" (p. 107). En este sentido, la perspectiva crítica asumida en estos microrrelatos hace eco de la reflexión propuesta por Lipovetsky (2000) acerca del proceso de personalización, en la medida en que denuncia los condicionamientos generalizados en la sociedad contemporánea en función de una voluntad de autonomía y liberación propia del individuo contemporáneo.

Dentro de este conjunto que trata a la ciudad como el producto de la acción de los habitantes hemos agrupado microrrelatos que aluden a tres modos sistemáticos de intervención sobre la organización social y el sistema de actitudes y valores: en primer lugar, aquellos que hablan de la desensibilización; en segundo lugar, los que se refieren a la rutina y, en tercer lugar, los que abordan modalidades de rebusque. Los tres subgrupos pueden ser entendidos como consecuencias de la intervención sobre el vínculo social (Berque, 1993) y los modos de interacción, en tanto la ciudad nos vuelve menos sensibles, nos "rutiniza" y nos empuja a actuar de una manera poco convencional, en cierta forma, desviada del canon social. 


\section{La desensibilización}

La desensibilización se trata de un problema que tienen los habitantes de la ciudad de Santiago a la hora de relacionarse con otros. Los textos hacen hincapié en la falta de interés en los demás y las dificultades de la vida en común producto de ese desinterés, así como en el anonimato que se vuelve invisibilidad e indiferencia. La reflexión hecha por Simmel (1989) a comienzos del siglo XX es interesante, puesto que, para el autor, la vida en la ciudad se caracteriza por la aparición de nuevas formas de sociabilidad, de un nuevo estado de ánimo y, como reza su célebre planteamiento, por una transformación en el orden de las mentalidades. Simmel prestó gran atención a la relación histórica entre la gran ciudad y las formas emergentes de individualismo.

Según el mismo autor, a diferencia de la sensibilidad y de las relaciones afectivas propias de las ciudades pequeńas, la vida en la gran ciudad se define por su carácter intelectual y por el establecimiento de relaciones racionales entre las personas - que son evaluadas de una manera objetiva, de acuerdo con su interés y su rendimiento concreto y no con la individualidad de las personas que participan en ellas-, lo que implicaría otorgar una tonalidad afectiva a la conducta (Simmel, 1989). En este sentido, la indiferencia no es el resultado de una no-consideración de los otros, sino de una alta atención, pero puesta en aspectos nuevos y específicos; una especie de indiferencia "por exceso y no por defecto” (Grafmeyer y Joseph, 1984, p. 44). Esta indiferencia por exceso es lo que Simmel denomina el carácter reservado: "La actitud mental de los habitantes de las grandes ciudades hacia los demás bien puede ser designada, desde un punto de vista formal, como un carácter reservado" (Simmel, 1989, p. 241. Traducción y cursivas propias). La reserva y la indiferencia traen condiciones de reciprocidad de la vida en la gran ciudad. Ellas implican el logro de una mayor independencia en relación con los demás y, en consecuencia, se convierten en la condición de posibilidad para la interacción en la ciudad (Grafmeyer y Joseph, 1984). Al mismo tiempo, se vuelven aspectos que pueden producir una sensación de soledad y abandono. A decir de Lipovetsky (2000): "Cuanto más la ciudad desarrolla posibilidades de encuentro, más solos se sienten los individuos" (pp. 77-78). Por un lado, se convierten en condiciones de libertad; por el otro, en productores potenciales de sufrimiento. Es este aspecto el que se torna objeto de crítica y juicio por parte de los concursantes.

En los microrrelatos que abordan la desensibilización, los autores se refieren a la constante sensación de invisibilidad que genera el Gran Santiago, al estar lleno de gente que recorre las calles y se moviliza en los medios de transporte con un objetivo claro que no tiene que ver con el contacto con los otros. Las dos grandes formas de hacer frente a esta desensibilización son la queja y la adaptación; esta última, en el caso de inmigrantes que llegan a la ciudad desde otras regiones del país.

\section{Queja}

La queja remite a una manifestación de incomodidad con dicha invisibilidad o con la no comprensión de cómo y por qué se produce. Existe una suerte de lamento ante la paradoja de ser invisible al estar rodeados de personas.

\section{Vientos de guerra}

Todos corren... apurados... ¿Hacia dónde van?... Durante el viaje me enamoré como dos veces, me despreciaron creo que cinco. Me asusta tanto la frialdad de los rostros del Metro flotando en el aire. Respiramos vientos de guerra mundial. ¿Qué pasaría si en este carro nos mirásemos de frente... ¡todos!, y olvidáramos que queremos olvidarnos, y recordáramos que nunca más nos veremos?... Juro por lo más preciado, que lo que digo sucedió... Súbitamente, todos se levantaron, se tocaron... y se besaron la mejilla. Yo, atónito desde mi asiento, ingresé entonces a la secta oculta de los viajeros del tren 102.

Pablo Figueroa, 33 años, Maipú. 
En estos microrrelatos se indica que la indiferencia es el estado anímico propio de los habitantes de la ciudad de Santiago. No obstante, se trata de un estado artificial, de algo producido y creado por los propios individuos. El microrrelato titulado "Vientos de guerra", con un tono dramático y casi religioso, se pregunta por qué la gente de Santiago se comporta así, en particular quienes utilizan el Metro como medio de transporte. Se trata de una "ciudad indiferente". Solo la gente que viene de provincias es capaz de tener intenciones sinceras y de conocer y reconocer a los otros habitantes de la ciudad. En este sentido, los participantes en el concurso hacen eco de la propuesta comprensiva de la vida urbana generada por Simmel y la Escuela de Chicago hace casi un siglo, en cuanto a su carácter anónimo y superficial.

\section{Adaptación}

La adaptación es una estrategia seguida, sobre todo por personas externas a la ciudad —inmigrantes-, proveniente de otros países, ciudades o regiones, que sienten la diferencia de este nuevo lugar en donde les toca vivir. Un lugar que no siempre es acogedor, en el que la relación entre las personas muchas veces está cruzada por la apatía o la indiferencia y sobre el cual hay que aprender nuevos códigos de conducta que posibiliten la vida cotidiana. En el caso del microrrelato “...Y paró” se muestra un comportamiento imitativo, que parte del reconocimiento del comportamiento típico de los urbanitas, pero deriva en una forma de ironía. El tono de la adjetivación del estilo de vida urbano es bastante negativo.

\section{...Y paró}

Esa ordinaria sencillez provinciana que me venía siguiendo como hedor desde el terminal de buses, no debía notarse. Bajé las escaleras con la nariz altiva y la dignidad al tope y esperé ese famoso "Metro" (respetuosa de la raya amarilla) en un estado artificial de santiaguina indiferencia. Y con la misma indiferencia y el aplomo recién estrenado, levanté mi brazo derecho y lo hice parar.

Silvia Guajardo, 54 años, Santiago.
Para los autores de los microrrelatos, la desensibilización propia de la vida en la ciudad se caracteriza por su efecto igualador sobre las personas, que se produce por diversos medios, pero todos de carácter cotidiano. Se repara en la sutileza de los mecanismos de control social y disciplina que van en contra de la realización individual, entendida como el motivo rector de la vida contemporánea (Lipovetsky, 2000). Así, los habitantes de la ciudad pierden aquello que los hace verdaderos seres humanos y se convierten en engranajes de una máquina, zombis o, incluso, ovejas, es decir, seres sin voluntad. Una vez ocurrido ese proceso, el intento de hacer distinciones entre las personas se vuelve imposible, porque han perdido todo aquello que les hacía únicos. Es lo que muestra el microrrelato "La identidad", cuyo valor no se encuentra tanto en el tono de queja o de adaptación que adopta, sino en que ilustra el proceso de desensibilización que culmina en anonimato. En él se describe cómo la posibilidad de ser y vivir en la ciudad y de ser reconocido dependen de la posesión de ciertos marcadores de estatus, sin los cuales el habitante carece de existencia: con cierta ironía nos muestra que, fuera de tales marcadores, las posibilidades de reconocimiento con otros son inexistentes.

\section{La identidad}

Juan, un día cualquiera, se encontró en pleno centro de la ciudad y se dio cuenta que no llevaba carné de identidad, tarjetas de crédito, dinero, traje formal, partidura, anillo de compromiso, cigarrillos. Ni siquiera rumbo llevaba. Fue entonces cuando desapareció.

Eric Moreau, 33 años, Santiago.

Muy ligado a lo anterior encontramos otro conjunto temático abordado por microrrelatos: la soledad (Posada, 2012). A decir verdad, la lógica que gobierna el sentimiento de soledad de los habitantes es aquella producida por la desensibilización y la indiferencia. Vale la pena abordar esta temática para destacar la generación e instalación de dos consecuencias de la lógica social indiferente: un pesar de orden existencial y un modo de vida solitario. Frente a la soledad, 
los habitantes de la ciudad parecen reaccionar simplemente en solitario. En este caso, los microrrelatos nos muestran que la soledad se camufla dentro de los comportamientos urbanos convencionales y pasa desapercibida. Indican formas en las que se manifiesta la necesidad de vínculo social, pero de un modo en el que no aparece explícita ni como tema en la comunicación o interacción con otros, sino como una suerte de pulsión realizada por medio de las opciones y los recursos que se encuentran más a mano para los habitantes.

En "Intimidad pasajera" vemos que la protagonista ha desarrollado una estrategia para hacer frente a su soledad: una estrategia corporal, que indica lo básico y profundo de su requerimiento social y afectivo. El texto invierte la consideración habitual del contacto físico en los medios de transporte para mostrar una dimensión posible de la soledad y el pesar existencial canalizados en una práctica oculta, invisible a ojos del resto. La soledad no es una banalidad, contrario a lo apuntado por Lipovetsky (2000).

\section{Intimidad pasajera}

Se llama Juana Catrilqueo Peña. Nació hace 63 años en Mantilhue, una localidad rural ubicada a $70 \mathrm{kms}$ de Osorno. A los 15 se vino a Santiago a trabajar como nana. Tuvo un hijo que murió atropellado en la Alameda el año 86. Desde entonces vive sola en una pieza que arrienda en Quilicura. Es callada, sigilosa y muchas veces pasa desapercibida. Viaja en micro todos los días a la casa de sus patrones y aprovechándose del tumulto y los apretones de una intimidad obligada, acurruca su cabeza en el hombro de otro pasajero sin que nadie se dé cuenta.

Gonzalo Andrade, 26 años, La Florida.

\section{La rutina}

Este grupo aglutina aquellos microrrelatos que tienen relación con la rutina diaria, el quehacer cotidiano, las responsabilidades y las formas convencionales de distribuir el tiempo y la vida. Con lo que se intenta lidiar aquí es con la monotonía de la vida, el aburrimiento, el cansancio, lo predecible que se hace cada día, los costos de no poder hacer aquello que reporta realización y felicidad, debido a que se debe responder ante las necesidades de la ciudad y sobrevivir por medio de un trabajo. En efecto, la rutina es observada en su relación con el mundo laboral y el impacto que tiene sobre la vitalidad y el entusiasmo de los habitantes de la ciudad. En estos casos, ocurre que, como efecto de las repeticiones permanentes en un trabajo que no permite la realización de los individuos, estos pierden su energía y determinación para hacer lo que quieren y para crear las condiciones de su felicidad. Es posible distinguir tres formas típicas de lidiar con la rutina: a) el escape por medio de la imaginación; b) la queja, y c) la intervención de la rutina o la generación de rutinas alternativas.

\section{Imaginación}

El escape por medio de la imaginación constituye la construcción mental de una situación distinta a la que se está viviendo, en general por medio de la asignación de un significado diferente a los componentes habituales de la experiencia y su articulación en un modo alternativo, fantasioso. El escape por medio de la imaginación puede implicar que el cuerpo funciona de modo mecánico, casi en modalidad de "piloto automático". El escape por medio de la imaginación suele adoptar un tono de autoconvencimiento; otras, de convencimiento de otros.

\section{El hípico}

"Estación Franklin", acota el conductor del Metro. Abre las puertas y todo cambia: “iiPaaaartieron!!... Morenaza toma la delantera. La sigue a dos cuerpos Flaco de Azul. Acercándose por fuera, Pingüino Cimarrero, deja en tercer lugar a Flaco de Azul, que se acerca a Morenaza. En el último lugar, Despistado Buscando la Salida... Entraaaaaaaaron a tierra derecha. Morenaza saca tres cuerpos de ventaja, mientras Flaco de Azul arremete, pasando a Pingüino Cimarrero... Milagrosamente, Despistado Buscando la Salida, como una flecha los sobrepasa... y por medio cuerpo de diferencia gaaaaana la carrera a la escala mecánica”.

Víctor Hugo Henríquez, 42 años, Santiago. 


\section{Hora de incidentes}

Espero el Metro. Siento un rumor desde el túnel y aparece una manada de rinocerontes. "Ahora sî", dice un jubilado al escuchar un pitazo, pero es el tren expreso a Chiguayante lleno de huasos agitando pañuelos. El público impaciente organiza una pichanga entre andenes: San Pablo 2, Escuela Militar 0. Por fin llega el Metro extrañamente iluminado, parece árbol de pascua. Subimos, está lleno de alienígenas que nos abducen. Nos encomendamos al Señor, Él nos escucha y somos liberados junto a la Virgen de San Cristóbal. El funicular no funciona, tenemos que bajar a pie... Por eso llegué tarde, Jefe.

Alfredo Cifuentes, 53 años, Independencia.

\section{Queja}

La queja remite a una sensación de aburrimiento, cansancio, decepción o frustración, producto de hacer lo mismo todos los días, lo que imposibilita hacer lo que se quiere hacer, como viajar, estar con los seres queridos, disfrutar de las familias. Esto muchas veces instala la pregunta de si se trabaja para vivir o se vive para trabajar. La queja es contra una rutina que deshumaniza.

\section{Un día más}

Me levanto y camino sigilosamente hacia tu dormitorio. No quiero despertarte. Abro tu puerta. Te veo, te huelo, te tapo y te beso. Micro y metro. Empujones y oficina. Pantalla. Mails. Órdenes y apuro. Café y pienso en ti. Teléfono. Teléfono. Teléfono. Hot-dog y trámite. Papeles. Miradas. Me rasco la cabeza. Reunión. Un pucho. Reunión y galletas. Un chiste, un amigo y el reloj. Apagar equipo. Metro y micro. Empujones y casa. Camino sigilosamente hacia tu dormitorio. No quiero despertarte. Abro tu puerta. Te veo, te huelo, te tapo y te beso. Mañana será otro día.

Daniel Carrasco Ruiz-Tagle, 36 ańos, Vitacura.

\section{Intervención}

La intervención de la rutina remite a la creación de "rutinas alternativas" o formas de modificar, de forma sencilla, la rutina diaria para poder llevarla por toda una vida o muchos años. Esta intervención se realiza en los intersticios que aparecen en la vida cotidiana y que parecen coincidir con aquellos intervalos en los que las vinculaciones a distintas instituciones sociales se atenúan. Es el caso del trabajo.

\section{Sobre azul}

Hoy es viernes y tengo que despedir a Sanhueza. Mi jefe piensa que ya se lo dije. Pero no es tan fácil. Sanhueza es como veinte años mayor que yo y, cuando llegué a la empresa, fue el único que no pensó que mi puesto lo merecía él. Desde mi oficina observo el Paseo Ahumada y podré ver cuando llegue. Él siempre anda acompañado de un libro. Ahora mismo debe venir en el Metro releyendo alguna historia de Cortázar o Borges, sus favoritos. "¿Para matar el tiempo, Sanhueza?”, le pregunté cuando recién nos conocíamos. "No", me dijo, "para hacerlo vivir".

René Allard, 41 años, Providencia.

\section{Mi vida}

Para vivir o realmente no vivir, he mantenido una vida paralela. Le dedico tiempo en la micro, en el Metro o unos minutos antes de dormir. A veces la dejo por unos días y la retomo después. A veces, según lo requiera, puedo sentir a alguien sentado a mi lado, poniendo su mano en mi hombro. Puedo sentir los besos de mi vida paralela, puedo sentir la pena, los abrazos, las dudas, puedo vivirla. Una de las cosas maravillosas que tiene esa vida, es que la puedo corregir. Pero lo que más me gusta es que tengo un invernadero.

Pabla Aguirre, 32 años, Puente Alto.

\section{El rebusque y la alternativa}

Por otro lado, los microrrelatos que analizamos dan cuenta de formas alternativas de vida que no se atienen a las exigencias ordinarias de la organización urbana; tienen que ver con la configuración de un modo de vida caracterizado por tener un trabajo estable, una familia, una casa que mantener, una rutina establecida. Frente a este modo de vida, hay microrrelatos que muestran la existencia de personas que no tienen horarios, no siguen los patrones establecidos, exhiben alternativas reales de vida, otros lugares, otros intereses, otras demandas, otras preocupaciones. Estos microrrelatos retratan formas de vida que pueden ser clasificadas como "anormales" e, in- 
cluso, si forzamos un poco los conceptos, lo que desde la teoría sociológica funcionalista se denominó “conductas desviadas” (Merton, 2002). Sin embargo, nos parece que lo más relevante de ellos es mostrar una opción frente a las convenciones del modo de vida urbano (Aguirre, 2007). Es el caso de los microrrelatos que abordan la prostitución, la informalidad y la mendicidad, entre otros.

\section{Prostitución}

La prostitución es abordada desde distintos aspectos, sobre todo, como una forma de vida que canaliza una problemática existencial o bien como una modalidad de dar respuesta a necesidades y requerimientos propios, en particular materiales. En ambos casos, se trata de una situación obligada o un estado al que se llega sin desearlo. El microrrelato "Mariposa nocturna” nos entrega una descripción de una rutina cargada de sinsentido. Se trata probablemente de un travesti que debe hacer frente a todos los problemas vinculados con su oficio, pero lo hace sin expresión de alegría ni de satisfacción. A pesar de que no hay recriminación moral, el texto transmite una importante dosis de pesadumbre existencial.

\begin{abstract}
Mariposa nocturna
La noche cae sobre Santiago y yo me apresto a un día más de ajetreos sin sentido. Ponerme aquellas faldas que cada vez cuestan un poco más, pintarme la cara, disfrazar mi olor con esencia de flores. Espantar a los babosos que me encuentro al salir de mi cuarto, para luego tomar un taxi y subir a Avenida Suecia. Deambular entonces por las esquinas esquivando mirones, esperando un auto que me lleve o alguna amiga que me anime.
\end{abstract}

Pablo Rojas, 21 años, Nuñoa.

\section{Informalidad}

Las referencias al trabajo informal ponen de manifiesto la existencia de un mercado alternativo, presente y al alcance de todos. Se muestra la existencia de formas de desenvolverse en el medio urbano, de cómo llevar una vida en la ciudad que termina cumpliendo un rol en el funcionamiento de la ciudad. Por ejemplo, en su condición ilegal, el vendedor ambulante se encarga de propagar la cultura, de dejarla al alcance de todo lector, en especial de aquellos que no pueden acceder a los circuitos oficiales o legales. Además, posee un conocimiento real de lo que hace: clasifica y recomienda libros mientras debe escapar de la policía. Por otra parte, las situaciones de informalidad muestran estilos de vida alternativos que no necesariamente están descritos de un modo triste o resignado; al contrario, se plantean como un tipo de comportamiento que evidencia los puntos débiles de las conductas normales.

\section{Los Clásicos}

"Pero hombre, cuántas veces te he dicho que tienes que partir por los clásicos. No es posible que no sepas distinguir entre un Cortázar y un Borges ¡Eso es imperdonable, im-per-do-na-ble!, sobre todo viniendo de personas como nosotros, que estamos aquí para propagar la cultura”. De pronto saltó como un resorte. “AApriete cachete compadre, que se vienen los pacos!”. Mientras desaparecía en la multitud con su bolsa bajo el brazo pensaba, que, aunque no le había convencido del todo el último de Vargas Llosa, igual se vendía bastante bien... después de todo era un clásico.

Cristian Martínez, 34 años, La Cisterna.

\section{Los chicos que nunca lloran}

Venden aspirinas, helados, libros piratas, agujas, pañuelos, imaginación es lo que venden. Se suben como gacelas a las micros, cantan tres frases cortadas de una canción, por el amor de Dios te dicen, deme una monedita, se bajan sobrecorriendo. Huyen de los carabineros, gritan sus mercancías, viven con el saquito a cuestas, son chacoteros, siempre con un chiste entre los labios, son los chicos de las calles de Santiago, curtidos por el clima y la vida, van de un extremo a otro, se mueven entre pobres y ricos, hacen piruetas y acrobacias entre los autos, lavan parabrisas y nunca lloran.

María Angélica Muñoz, 45 años, Dorsten, Alemania.

\section{Mendicidad}

Este subgrupo nos da cuenta de una forma de lidiar con la ciudad que se produce en las calles, en los rincones, por parte de personas que viven 
y se desarrollan allí. Se nos muestran distintos aspectos de este estilo de vida, pero sobre todo, se le caracteriza como el resultado del funcionamiento de los problemas de la vida en la ciudad antes descritos. La mendicidad es la consecuencia de los problemas de las relaciones con otros, como vimos a propósito de la desensibilización y la rutina; son los problemas con el vínculo social los que ponen a los vagabundos y mendigos en una situación en la que obligadamente deben lidiar con el frío, el hambre y el abandono.

\section{Una noche en Santiago}

La lluvia golpeaba fuerte su ventana, el intenso frío estaba congelándolo. Se sentía hambriento y demasiado cansado luego de un arduo día de trabajo. Sintió pasos... No tenía hora, pero sabía que la gente cesaba de concurrir a esa céntrica calle santiaguina mucho antes. Temió por su vida... Ya antes lo habían invadido y lo golpearon tan fuerte, que no pudo moverse en una semana. Los pasos se acercaban... Tomó su arma y esperó en silencio. El intruso se detuvo junto a él, ofreciéndole una caja de vino. Soltó entonces la piedra, retiró los diarios que le cubrían y sonrió.

Enrique Rodríguez, 23 años, Padre Hurtado.

\section{Conclusiones}

A continuación proponemos tres conclusiones generales a partir del análisis aquí desplegado. Las dos primeras refieren a hallazgos provistos por el análisis temático efectuado: la primera, en relación con la noción de repertorio; la segunda, aborda el tipo de comprensión subjetiva de las formas de lidiar con la urbe; la tercera, consiste más bien en una reflexión relativa a la producción de representaciones e imaginarios a partir del tema que nos convoca.

\section{Tres registros típicos}

De acuerdo con el análisis expuesto en las páginas anteriores, nos parece razonable proponer que las representaciones de las formas de lidiar con la urbe hechas en los microrrelatos adoptan, en su mayoría, los registros de: a) la queja; b) la adaptación, y c) la innovación/alteración. Cuando se trata de expresar los distintos problemas o fenómenos molestos a los que deben hacer frente los habitantes de la ciudad, en particular lo referido al plano de la sociabilidad, que es el aspecto más considerado, los textos adoptan uno de los tres registros señalados (queja, adaptación o innovación/alteración). Tales registros aparecen a veces de modo aislado en un texto, mientras otros lo hacen de manera imbricada.

En términos generales, la temática de la desensibilización corresponde a una forma de queja respecto al modo de vida urbano y la rutina se presenta como la principal modalidad adaptativa - deseada o no- a dicho modo de vida. El rebusque y la alternativa dan cuenta de formas de innovación y alteración de las convenciones que gobiernan el estilo de vida urbano. De ello desprendemos la posibilidad de sugerir un repertorio de formas de lidiar con la urbe, no en el plano de los contenidos específicos, sino en uno pragmático: el repertorio estaría compuesto por tres registros o modos característicos mediante los cuales se transmite un tipo de relación que establecen los habitantes con los problemas de la vida urbana, así como unas formas específicas de acción: en ese sentido, puede pensarse que la secuencia típica es la de quejarse y luego adaptarse para, en ciertas circunstancias, generar modos de acción alternativos.

\section{Una secuencia causal}

En relación con el tipo de comprensión que tienen los habitantes de las formas de lidiar con la urbe, son concebidas como problemas o situaciones que afectan a los habitantes de la ciudad desde fuera, esto es, como problemas o fenómenos molestos que no se originan en el individuo, sino en los modos colectivos de acción: la gente actúa de un determinado modo en la ciudad y eso es lo que afecta a cada persona. Esto quiere decir que la gente se comporta de una forma particular, 
ese comportamiento afecta el vínculo que se establece entre las personas y luego ese malestar se expande al fuero más íntimo de cada habitante.

El ejemplo más claro lo proporciona la secuencia que va de la desensibilización al anonimato, para llegar a la soledad. En efecto, el ámbito en el que se problematiza la desensibilización es fundamentalmente el del modo de vida urbano y de los esquemas de reconocimiento de los otros, esquemas que se encuentran generalizados entre los habitantes de la urbe. El anonimato, por su parte, remite a una erosión en los principios y factores que posibilitan la interacción con los otros. Por último, la soledad es problematizada en el registro existencial y en el modo de la pesadumbre existencial.

Creemos que hay aquí una pista para entender los modos de representación y comprensión de la ciudad y la vida urbana por parte de nuestros contemporáneos. En efecto, la secuencia causal aludida sugiere que la fuente productora de aquellos elementos desagradables y molestos con los que deben lidiar se encuentra más allá de los individuos, en el orden "supraindividual" apuntado por Morand (1977) y, en consecuencia, sugiere que el modo de vida urbano adquiere la textura propia de un "hecho social" (Durkheim, 1984, p, 31) que, en su carácter coercitivo, se impone a los individuos. Vista así, la comprensión de la ciudad que tienen los autores de los microrrelatos resulta, en cierta forma, ejemplar del "mito de la sociedad urbana" descrito y criticado por $M$. Castells (1971), según el cual la cultura urbana tiene su origen en un marco ecológico particular y no en contradicciones $u$ oposiciones estructurales de una sociedad histórica específica.

\section{Una legibilidad procesual y progresiva}

Como señalamos al inicio, una constelación temática constituye una forma parcial de legibilidad de la ciudad que, al mostrar el aspecto específico que la conforma, sugiere la existencia de otros posibles y, en consecuencia, para tener una visión más completa de la ciudad, es necesario abordar esos otros aspectos. Resulta claro que los microrrelatos que analizamos, en la mayoría de los casos y tomados de modo individual, no son capaces de ofrecer perspectivas interpretativas complejas de la ciudad. De hecho, es al realizar un tratamiento del conjunto de ellos o del concurso en su totalidad que esto se vuelve posible, como atestigua lo que hemos planteado en este trabajo.

Esto tiene varias consecuencias en el orden de las representaciones de la ciudad. En primer lugar, indica que producir visiones un tanto más complejas que las que genera un microrrelato aislado - como las que aquí hemos propuesto- solo es posible en la medida en que se desarrolle una lectura relativamente sistemática de los textos publicados por el concurso. Por lo tanto, las lógicas y secuencias que hasta aquí hemos expuesto solo se insinúan al lector común y corriente de los microrrelatos en el Metro.

En segundo lugar, el procedimiento analítico "agregativo" aquí desplegado contiene en sí mismo un efecto representacional peculiar: el trabajo ha consistido en revisar una y otra vez los textos para ir identificando recurrencias y similitudes. No obstante, al hacerlo constatamos una gran variedad de temas, lo que recuerda el postulado de Perec (1974) que mencionamos al inicio: la ciudad es una entidad demasiado grande para intentar definirla de una sola vez. Ello sugiere que si la ciudad es a menudo considerada como una aglomeración — la denominada "aglomeración urbana”-, los microrrelatos muestran que también puede ser concebida como una suerte de aglomeración temática.

La idea de aglomeración temática presupone el carácter incompleto de esta forma de representación de la ciudad, es decir, su carácter temporal y provisorio. Esto es importante para un artículo como este, cuya pretensión es comprender de mejor manera las formas de lidiar con la 
urbe desde el punto de vista de los propios actores que las experimentan, las sufren y les dan vida: las formas de lidiar con la urbe son cambiantes y dinámicas, como lo es la experiencia de cada habitante. La visión "aglomerativa” indica, en consecuencia, que ellas también son variadas y cambiantes y que su comprensión requiere dar cuenta de esta radical condición histórica.

\section{Bibliografía}

Aguirre, L. (2007). La violencia en el espacio urbano y el derecho a un mejor vivir. INVI, 22(61). Recuperado de http://www.revistainvi.uchile.cl/ index.php/INVI/article/view/278/252

Aliste, E. y Musset, A. (2014). Pensar los territorios del desarrollo: sustentabilidad y acción pública en nombre de una ciudad imaginaria. Concepción (Chile), 1950-2010. EURE, 40(120). Recuperado de http://www.scielo.cl/ scielo.php?pid=S0250-71612014000200005\&script=sci_arttext

Barrère, A. y Martuccelli, D. (2009). Le roman comme laboratoire. De la connaissance littéraire à l'imagination sociologique. Villeneuve d'Ascq: Presses Universitaires du Septentrion.

Barthes, R. (1985). L'aventure sémiologique. París: Seuil.

Becker, H. y Faulkner, R. (2011). El jazz en acción. La dinámica de los músicos sobre el escenario. Buenos Aires: Siglo XXI.

Bernasconi, O. (2011). Aproximación narrativa al estudio de fenómenos sociales: principales líneas de desarrollo. Acta Sociológica, (56), 9-36.

Berque, A. (1993). Du geste à la cité. Formes urbaines et lien social au Japon. París: Gallimard.

Boisier, S. (1989). Los siete pecados capitales de la capital y el desarrollo de la región del Bío-Bío.
Un binomio para potenciar la calidad de vida. EURE, 15(46), 7-15.

Campos, L. (2011). Les enjeux de la représentation de la ville: Santiago du Chili en cent mots. Saarbrücken: Editions Universitaires Européens.

Carrión, F. y Núñez-Vega, J. (2006). La inseguridad en la ciudad: hacia una comprensión de la producción social del miedo. EURE, 32(97), 7-16.

Castells, M. (1971). El mito de la sociedad urbana. EURE, 1(3), 27-41.

Chalvon-Demersay, S. (1994). Mille scénarios: une enquête sur l'imagination en temps de crise. París: Métailié.

Chalvon-Demersay, S. (1996). Une société élective. Terrain, (27), 81-100.

Correa, G. (2010). Transporte y ciudad. EURE, 36(107), 133-137.

Durkheim, E. (1984). Las reglas del método sociológico. Buenos Aires: La Pléyade.

Fernándes, E. (2014). Del Código Civil al Estatuto de la Ciudad: algunas notas sobre la trayectoria del Derecho Urbanístico en Brasil. EURE, 29(87). Recuperado de http://www.scielo.cl/ scielo.php?pid=S0250-71612003008700005\&script $=$ sci_arttext

Fernández, J.-L. (2005). Hacia la conformación de una matriz genérica para el microcuento hispanoamericano. Literatura y lingüistica, (16), 107-134.

Friedmann, J. (1997). Futuros de la ciudad global. El rol de las políticas urbanas y regionales en la región Asia-Pacífico. EURE, 23(70). Recuperado de http://www.scielo.cl/scielo.php?script=sci_arttext\&pid=S0250-71611997007000003

Grafmeyer, Y. y Joseph, I. (eds.) (1984). Présentation. La ville comme laboratoire et le milieu 
urbain, en L'école de Chicago. Naissance de l'écologie urbaine (pp. 7-49). París: Aubier Montaigne.

Iracheta, A. (2011). La necesidad de una política pública para el desarrollo de sistemas integrados de transporte en grandes ciudades mexicanas. INVI, 26(71), 133-142.

Irarrázaval, F. (2012). El imaginario "verde" y el verde urbano como instrumento de consumo inmobiliario: configurando las condiciones ambientales del área metropolitana de Santiago. INVI, 27(75), 73-103.

Koonings, K. y Kruijt, D. (eds.) (2007). Fractured Cities: Social Exclusion, Urban Violence and Contested Spaces in Latin America. Nueva York: Zed Books.

Lassave, P. (1998). La ville entre les signes de la science et du roman. Espaces et Sociétés, (94), 11-29.

Lassave, P. (2002). Sciences sociales et littérature: concurrence, complémentarité, interférences. $\mathrm{Pa}$ rís: PUF.

Lewis, O. (1988). La cultura de la pobreza. En M. Bassols, R. Donoso, A. Massolo y A. Méndez (comps.), Antología de Sociología Urbana (pp. 240-251). México: UNAM.

Limón L., P. (2014). Imaginación geográfica y agencia política: produciendo espacio público a través del Derecho en Madrid (1992-2012). EURE, 40(120), 183-200.

Lipovetsky, G. (2000). La era del vacio. Ensayos sobre el individualismo contemporáneo. Barcelona: Anagrama.

Merton, R. (2002). Teoría y estructura sociales. México D. F.: Fondo de Cultura Económica.

Mondada, L. (2000). Décrire la ville: la construction des savoirs urbains dans l'interaction et dans le texte. Bruselas-París: Anthropos, Économica.
Morand, C. (1977). Visión de Santiago en la novela chilena. Santiago: Ediciones Aconcagua.

Moser, C. y Mcllwaine, C. (2005). Latin American Urban Violence as a Development Concern: Towards a Framework for Violence Reduction. World Development, 34(1), 89-112.

Muller, P. (2010). Secteur. En L. Boussaguet S. Jacquot y P. Ravinet, Dictionnaire des politiques publiques (pp. 591-599). París: Presses de Sciences Po.

Musset, A. (2007). Entre la ciencia ficción y las Ciencias Sociales: el "lado oscuro" de las ciudades americanas. EURE, 33(99), 65-78.

Perec, G. (1974). Espèces d'espaces. París: Galilée.

Posada, J. (2012). El espacio, la verificación de la soledad. Bitácora Urbano Territorial, 21(2), 157-164.

Riessman, C. (2008). Narrative Methods for the Human Sciences. Londres: Sage.

Sabatini, F., Rasse, A., Mora, P. y Brain, I. (2012). ¿Es posible la integración residencial en las ciudades chilenas? Disposición de los grupos medios y altos a la integración con grupos de extracción popular. EURE, 38(115), 159-194.

Searle, J. (1982). Sens et expression. París: Les Editions de Minuit.

Simmel, G. (1989). Philosophie de la modernité. La femme, la ville, l'individualisme. París: Payot.

Stierle, K. (2001). La capitale des signes. Paris et son discours. París: Editions de la MSH.

Wirth, L. (1984). Le phénomène urbain comme mode de vie (1938). En Y. Grafmeyer e I. Joseph (eds.), L'école de Chicago. Naissance de l'écologie urbaine (pp. 251-277). París: Auber Montaige. 